\title{
ENVIRONMENTAL EDUCATION, SOCIAL JUSTICE AND TEACHER EDUCATION: ENABLING MEANINGFUL ENVIRONMENTAL LEARNING IN LOCAL CONTEXTS
}

\author{
C. Reddy \\ Department of Curriculum Studies \\ Faculty of Education \\ Stellenbosch University \\ e-mail: cpsr@sun.ac.za / https://orcid.org/0000-0002-6261-0600
}

\section{ABSTRACT}

Short $(2010,7)$ indicates that continued global population growth, technological advancement and subsequent burdens on the natural world from consumer demands during the $20^{\text {th }}$ century has led to many environmental issues and concerns. According to (Edwards 2011) the resultant or consequent problems in the environment could reach levels that could push the planet to levels of ecological disaster. Evidence of ecosystem destruction, human induced climate change, social injustice and increasing economic strife is mounting in many parts of the world. Environmental Education (EE) has often been mentioned as an important response to the issues mentioned above, but if EE is to contribute to the transformation to sustainable living, teachers have a vital role to play. Thus, teacher education programmes need to prepare preservice adequately for these challenges arising in the $21^{\text {st }}$ century.

This exploratory theoretical article reviews approaches and ideas for the development of curriculum for environment related education in teacher education programmes. I draw on the work of Short (2002) related to place based collaborative knowledge production and Jickling and Wals (2008), active and co-operative learning in context, to inform curriculum development possibilities for EE. The research highlights the importance of active participation for meaningful environmental learning and presents arguments for including local environmental issues and knowledge development during the practicum as key activities to enable meaningful environmental learning and social justice in teacher education programmes.

Keywords: environmental education, teacher education practicum, meaningful environmental learning, local contexts

\section{INTRODUCTION}

In the current period of global political and economic instability, with rising inequality and social unrest, the role of education in society is important, but also vulnerable. This is particularly true in South Africa where socio-political instability and inherent vulnerabilities in society have impacted on educational systems. These challenges affect all levels and role players of education, from individual students to teachers, through to systemic levels of 
operation governed by policy imperatives. Teacher education policies (DHET 2015) have recently been re-formulated at national level and requires implementation currently. This reformulation involved restructuring of teacher education programmes and adaptations to align with the "new" national qualifications framework developed for higher education. An important adjustment to the updated policy has been a bigger emphasis on the environment and inclusion of issues in teacher education curriculum.

Since the early 1970s, there has been a growing awareness of the negative consequences of most human-environment interactions. Amidst all of this uproar there is often a call for education to "do something" to address the problem. Environmental education (EE) has in many ways been a response to the perceived environmental crisis on local and global levels for almost forty years. According to Henderson et al. (2017), there has as yet been only limited attention to environmental problems such as climate change in educational research and in educational foundations. Education is however key to assisting humanity in mitigating and adapting to major environmental problems and key to developing sustainable living practices in future citizens.

The inclusion of EE or environmental oriented work has not been easy in teacher education programmes. Much of this is highlighted by Reddy (2017) and discussed briefly later in this article. Environment and knowledge of the environment is not easy to locate in education and particularly in teacher education. This presents challenges for the fields pertaining to research and curriculum development. Unlike many "traditional" disciplines, environmental education does not have a well-documented extant knowledge and is seemingly difficult to integrate into professional education programmes for teachers.

This article deals with the structure and design of training programmes for teachers generally and the current policy and programmes in the SA context. I highlight current environment related concerns, discuss environment related education briefly and explore and discuss ideas and practices related to how we might nurture and encourage positive change for inclusion of EE, through innovative and creative ways. In this regard I engage with active learning approaches pedagogies with a view to developing investigative and experiential approaches in local environments as a process for educating future teachers for education for sustainability and social justice as a response to human generated problems in the environment.

\section{ISSUES AND PROBLEMS IN THE ENVIRONMENT}

In documenting the history of the earth, geologists have developed various time periods or epochs. The current period during which humans have been dominant and had a significant impact on the earth and natural systems is called the Anthropocene. This period is thought by 
many to have started after the Second World War when there was a need to restructure and rebuild infrastructure and economies that were had all but been destroyed during the Second World War in Europe and other countries (Economist 2018). This period, the Anthropocene, is characterised by of almost unbridled economic development and industrialisation and during which humans have become central to all considerations during this period defined as the Anthropocene as indicated above. It is considered to be the period of the earth's history during which humans are determining how nature works and have a huge influence on natural processes.

Rocktrom et al. (2009) highlight scientific evidence that is beginning to suggest that humanity is beginning to overstep the ecological conditions that sustain our species. According to Crist (2013), the earth's climate is warming up at an accelerated rate as a result of human activity on the planet, the atmosphere and oceans have warmed, there are lower amounts of snow and ice and sea levels have risen due to industrialisation and carbon intensive living. The emissions of greenhouse gases are the highest in history, and Pachuari et al. $(2014,2)$ mention this as further evidence of human impact on climate system

Climate change is taking on increasing importance as we begin to feel the physical effects of the climatic changes in our daily lives. Some of the effects include increased frequency of extreme weather events such as cyclones and tornados, more frequent cycles of floods and droughts, reduced agricultural yields, quicker melting of the polar ice caps and the extinction of plant and animal species. Climate change has also had an impact on both the natural world and human societies and major societal impacts include threatened food supplies, increased poverty and poor economic activity, as indicated by Brennen and Quinton (2020).

Natural systems have also undergone severe degradation due to human activities leading to what is commonly termed socio-ecological strife. An international research think tank, the Intergovernmental Science-Policy Platform on Biodiversity and Ecosystem Services (IPBES) Global Assessment Report on Biodiversity and Ecosystem Service issued on 23 March 2018 discusses the main causes of species loss and mentions factors impacting on the migration of millions of people. It indicates that the worsening land degradation caused by human activities such as agriculture and industrial activities is undermining the well-being of two fifths of humanity, leading to species extinctions and intensifying climate change. The rapid expansion and unsustainable management of farming is the most extensive cause of land degradation, causing significant loss of biodiversity and ecosystem destruction. Wetlands have been particularly impacted, with losses of 87 per cent in wetland areas since the advent of the modern era (Anthropocene), and 54 per cent since 1900.

The report further indicates that the indirect drivers of land degradation are the high- 
consumerist lifestyles in the most developed economies, combined with rising aspirational consumerist living in developing / emerging economies. This rising per capita consumption, coupled to continued population growth in many parts of the world, can lead to an increase in unsustainable levels of agricultural expansion, natural resource and mineral extraction, and urbanisation, which can typically lead to greater levels of land degradation as indicated in the IPBES (2018) report. Currently less than 25 per cent of the earth's land surface has not been substantially impacted on by human activity; experts estimate that this will fall to less than 10 per cent by 2050 if current trends continue.

Working on reversing and restoring the problem of degraded land, needs to be prioritised to protect the biodiversity and ecosystem services vital to all life on earth including human wellbeing. These include food security, water purification, the provision of energy, (IPBES 2018). Human made climate change and its broad socio-ecological impact on the planet is a global challenge and education is key to assisting humanity in mitigating the ravaging effects of climate change.

\section{ENVIRONMENTAL EDUCATION: A RESPONSE TO THE CRISIS}

The complex field of EE has been in existence for almost four decades and had its origins at the same time as the organisations linked to socio-ecological oppositional protests. It has become a dynamic field constantly engaging with and responding to what is commonly referred to as the environmental crisis. In this section I highlight important instances in the journey of EE internationally and also refer to moments in the development of EE locally. EE has been defined in terms of understandings of the concept environment and as this broadened and changed the description and understanding of EE changed. The essential description presented by Sauve' $(2002,1)$ will be used as a frame of reference EE in this article

"EE is therefore not a form of education among many others; it is not simply a tool for environmental problem-solving or management. It is an essential dimension of basic education that lies at the root of personal and social development: the sphere of relationships with our environment, with our common home of life."

The field of environmental education emerged from the growing awareness of the problems related to the environment during the 1960 and 1970's. Gough $(2017,890)$ highlights that at this time the environment was seen as a set of interdependent natural ecosystems with the environmental crisis being understood as a consequence of the pollution of land, air and water, the increase in human populations and the depletion of renewable and non-renewable natural resources. International agencies such as the United Nations Educational, Scientific and 
Cultural Organization (UNESCO) and the United Nations Environment Programme (UNEP 1976) spearheaded the genesis of EE. This included international conferences in the 1960's in the cities of Belgrade and Stockholm and a conference in Tiblisi in Georgia in the 1970's. The resolution that emerged from the Tiblisi conference was that EE should be a process aimed at developing a world population that is aware of and concerned about the total environment and its associated problems. Such a population also needs to have the knowledge, attitudes, motivation, commitment and skills to work toward solutions of current environmental problems and the prevention of future problems.

Another landmark event that had strong implications for the direction taken by the field of EE was the 1992 United Nations Conference on Environment and Development held in Rio de Janeiro in the early 1990's. The term sustainable development and a set of principles for sustainable living originated from the deliberations at this conference. The declaration of a Decade of Environmental Education for Sustainable Development (2005-2014) emerged from the World Summit on Sustainable Development in Johannesburg in 2002. South Africa and many other countries, were signatories to this declaration which required countries to include EE in formal education curricula. The global education community's most recent international policy guide is: Education 2030: Incheon Declaration and Framework for Action and development (UNESCO 2015EDS). This document links the concept of quality education to Education for Sustainable Development (ESD) with the argument that ESD has the potential to enrich the acquisition of other fundamental competencies such as literacy and numeracy (United nations 2015,12 ). It is also linked to sustainable development goal 4 which includes a call for all learners across the world to acquire knowledge and skills needed to promote sustainable development (UNESCO 2015, 15).

Fein (1991) suggests that there has been a historical inattention to the inclusion of EE in teacher education programmes globally. He adds that the role of teachers as change agents is vital if $\mathrm{EE}$ is to contribute to the development and shift to sustainable living and development, (Fein 1991). Gough (2009) indicates that while EE in teacher education has long been advocated and attempts made at inclusion in terms of UNESCO UNEP since the late 1980's to the World Summit on Sustainable development (2002), there is overwhelming evidence bearing testimony to the almost universal lack of success in introducing programmes of EE in teacher education programmes. Research also indicates that attempts at including EE in teacher education programmes are often met with barriers of various kinds. These are described and highlighted by Reddy (2017) and include knowledge issues and disciplinary position, Corney and Reid (2007, 34), programme issues McKeown-Ice (2000, 10), policy weaknesses, Ormond et al. (2014), and subject / subject matter issues, Van Petegem, Blieck and De Pauw (2007). 
In the next section I focus on the field of teacher education to review how EE might be infused into TE programmes particularly in South Africa in terms of the current policies.

\title{
TEACHER EDUCATION: A SPACE FOR EE?
}

Brennen and Quinton (2020) indicate that although realised in different historical circumstances teacher education programmes in many countries share common features. They are generally coupled to government policies, operate within universities and have been tied to global policy trends and shifts but with particular effects in different countries. Brennen $(2017,55)$ writes

\begin{abstract}
"Governments have sought to constrain and improve teacher education in the interest of international competitive struggles. Within the terms of this struggle between the state and teacher education we argue that there is an urgent need for attention to the everyday work of teacher educators, their students and the school systems they serve - the practice of teacher education, which is to say the 'soul' or animus that makes teacher education what it is."
\end{abstract}

In the above quotation Brennen highlights how the essence and key practices of the field are often obscured by policy dictates and political trends. She indicates the need for introspection so as to highlight important issues for the field in the various contexts of practice. Environmental issues and problems which represent socio-ecological issues of the $21^{\text {st }}$ century are certainly relevant in this regard and a part of the thrust of this article.

Garm and Karlsen (2004) write that teacher education programmes are generally viewed as the formal preparation of teachers for professional work. Typically, teacher education programmes are made up of courses which include content areas informed by disciplinary knowledge, and also include content knowledge in education related aspects of philosophy, history, education psychology and sociology of education. Programmes generally also cover skills in assessing student knowledge, content or subject matter knowledge and methods for teaching a subject area and practice at classroom teaching through practicum experiences at schools (Brennen 2017). Sanford, Hopper and Starr (2015) indicate that the knowledge and processes embedded in these content (subject) areas have developed over many decades and represent a sincere commitment to the preparation of new generations of teachers with professional knowledge and skills to be effective teachers. Furthermore, these content areas compete for curriculum time in order that this curriculum knowledge can be introduced to the pre-service teachers by way of lectures, activities and assignments.

Many, including Sanford, Williams, Hopper and McGregor (2012) and Davis and Sumara (2012) critique the industrial model on which teacher education programmes are built, with discrete courses that separates knowledge from context and which is informed by a 
compartmentalised view of reality. Cochran-Smith and Zeichner (2010), suggest that there are various ways of reforming teacher education so that new teachers can thrive in the complexity of today's classrooms and schools. Sanford et al. (2015) in turn suggest that we need to rethink the ways in which teacher education programmes are oriented and what we seek to accomplish with teacher education as an area of professional learning. Areas that require review in their opinion include how courses are developed, conceptualised and interlinked, how learning is shared between students and staff and how knowledge not just professional, but also embedded knowledge in real / authentic contexts of practice is understood and reapplied. They offer a relational approach to knowing as an alternative to technical understandings that limit growth. They further suggest being flexible and adaptable as important principles for accommodating change and shifts in programmes.

Brennen (2017) indicates that (teacher education) curriculum needs to take the imperative for planetary wellbeing on board in order to contribute to sustainable living and sustainability. This presumably can be seen as advocacy for the inclusion of EE in teacher education. Stengers (2015) in Brennen (2017) indicates that we should think from where we are and act on the issues which are problematic in that site, rather than focusing on policy only. She agitates for a pragmatic approach to teacher education curriculum development which provides for ways to create new configurations of practice in which EE can be included in teacher education.

What is the teacher education scenario in South Africa (SA) and how do policies for teacher education work? All professional qualifications in the education sector are governed by a policy, the Minimum Requirements for Teacher Education Qualifications (MRTEQ), developed in the Department of Higher Education and Training (DHET 2011) document. MRTEQ provides guidelines for programme development and the qualifications requirements for teachers and other education professionals. The policy also provides articulating guidelines that align education qualifications with the National Qualifications Framework (NQF) and the Higher Education Qualifications Framework (HEQF).

In SA the focus in teacher education is on knowledge and teachers are described as knowledge professionals. Green (2012) describes the knowledge required by teachers as more than inert subject matter knowledge but rather an active form of knowledge that manifests as questions of, what, how and why, in moments of practice. This mandated knowledge theme is presented in MRTEQ policy as a knowledge mix (DHET 2011) required for all teacher training levels. The mix includes:

- Disciplinary learning - (the focus is on subject knowledge and learning theories)

- $\quad$ Pedagogical learning - (this refers to general pedagogies and for particular subjects) 
- $\quad$ Practical learning - (learning the work of a teacher during and from practice)

- Fundamental learning - (this includes language competence, and academic literacies such as ICT)

- $\quad$ Situational learning - (self, situations, contexts and environments).

\begin{tabular}{|c|c|c|c|c|}
\hline \multicolumn{5}{|c|}{ SUGGESTED INTEGRATED AND APPLIED KNOWLEDGE (MRTEQ) } \\
\hline $\begin{array}{l}\text { Disciplinary } \\
\text { Learning }\end{array}$ & $\begin{array}{l}\text { Pedagogical } \\
\text { Learning }\end{array}$ & $\begin{array}{l}\text { Practical } \\
\text { Learning }\end{array}$ & $\begin{array}{l}\text { Fundamental } \\
\text { Learning }\end{array}$ & $\begin{array}{l}\text { Situational } \\
\text { Learning }\end{array}$ \\
\hline
\end{tabular}

Figure1: MRTEQ diagram - knowledge domains for the knowledge mix

The main thrust of the policy dictates that teachers be trained as subject specialists in a minimum of two school subjects (disciplinary learning). Programmes also need to cover all the other components illustrated in Figure 1. This policy however does allow for space for institutional and regional innovation and implementation in terms of the knowledge mix presented, particularly practical and situational learning. More recently in an updated MRTEQ policy document (DHET 2015) the environment and sustainable development are clearly mentioned as ideas that need attention in teacher education in South Africa. This in my opinion represents the "crack" mentioned by Gough (2017) that can let the EE light into practice in teacher education and allow for the inclusion of local environmental issues as curriculum content in programmes.

\section{Environmental education and teacher education - a call to action}

Calls to include environment and issues of the environment in formal curricula for education institutions have been ongoing in all parts of the world for decades. In South African the right to a healthy environment is endorsed constitutionally and consequently environment has been included in formal education. This curriculum process was initiated by the White paper on education (1995) and concretised as part of the major curriculum change for schools in1997. This impacted on teacher education as this is where educators are introduced to teaching about environmental issues. The current policy update further ensures that environment is an important topic for teacher education curricula, (DHET 2015) and it is therefore imperative that EE is included in teacher education curricula.

How might teacher education programmes accommodate flexible ways of doing that are outside of the technocratic and mechanical approaches for teacher education as critiqued 
earlier? How might EE knowledge be included in the already crowded knowledge based teacher education curriculum in ways that ensure environmental issues are not just an "add on" but an integral part of the curriculum?

Nsubaga $(2020,104)$ writes that there is a growing interest worldwide in meaningful environmental learning largely linked to the dissatisfaction and general unhappiness over the failure of current pedagogical practices. The lack of opportunity that traditional information transfer teaching methods present for learners to engage in authentic real-life environmental problem solving is a major issue for environmental educators. Nsubaga $(2020,104)$ presents a typology / categories of teaching which ranges from of unidirectional teaching and information transfer to experiential, investigative and action taking approaches and suggests active learning approaches (experiential and investigative) as best suited as pedagogies for EE. During active learning processes learners / students are involved in doing things and critically thinking about the things they are doing (Nsubaga 2020, 105). Models of process like the active learning framework developed by O Donoghue (2005), discussed by Nsubaga $(2020,107)$ can be employed fruitfully as it provides opportunities for investigating issues in context, making progress towards solving environmental problems as well investigating root causes of the problems. Active learning is widely recognised as an important teaching and learning approach that can facilitate the realisation of outcomes of meaningful environmental learning suggested by Rosenberg $(2009,6)$ :

- $\quad$ Active and responsible citizenship

- A sense of hope and ability to imagine new possibilities

- Technical knowledge, insights and understanding

- Conceptual skills like enquiry, reasoning and drawing conclusions

Do teacher education programmes provide space for active and meaningful environmental learning outcomes detailed above? As indicated the general structure of teacher education programmes have areas of content knowledge in education foundations, subject matter knowledge and some form of professional learning or teaching practice periods at schools. It is my contention that the space for EE and active learning, given the problematic nature of subject matter for EE, would be in the practicum arena. During these periods, students are immersed in local communities which present contextual environmental issues and problems and the opportunity for supported active learning and co-production of knowledge.

What is the general view of practicum and its value to teacher education programmes? Ulvik and Smith $(2011,520)$ suggest that the main objective of the practicum periods in teacher 
education is to provide pre-service teachers with hands-on experiences of teaching in real world settings. This provides opportunities for students to develop their teaching competencies and to start gaining experiences which can serve to enrich their professional wisdom (phronesis) over time. They indicate that reading about teaching or observing others teach is not enough, they have to practice teaching themselves in real situations because practical knowledge and practical wisdom are developed and held by individuals and is rarely if at all transmitted from one person to another. According to these authors, student teachers need knowledge of how to teach (techné)) and by connecting the skills of teaching they learn to broader and subject knowledge (episteme (knowing), and through reflection, they will gradually start developing practical wisdom (phronesis), according to Ulvik and Smith (2011). However, to reach beyond their current level of personal personal it is useful to be guided by someone who is more experienced, often the person of the mentor teacher at school, where students are placed during the practicum. But how might local context knowledge and active learning be integrated into teacher education programmes and the practicum in particular?

I use the work of Short (2002) related to practical knowledge in local contexts to discuss the possibilities for inclusion of EE knowledge teacher education curriculum. I then link this with ideas from Jickling and Wals (2008) related to active learning / student centred practices to frame EE teaching and active learning in initial teacher education to ensure meaningful environmental learning.

\section{Practical knowledge and EE for teachers}

Short (2002) develops two conceptual distinctions for developing curriculum in higher education institutions such as universities. His point of departure is that all universities have the function of producing knowledge through research processes by way of particular methods linked to the disciplines. He indicates that universities contribute to the knowledge base of subject disciplines through research processes. He indicates that conventionally knowledge is generated by way of particular modes of enquiry that suit the practices and methods appropriate to the particular discipline. He adds that the curriculum content and what is taught is influenced by the activities of research foregrounded in the disciplines, (Short 2002).

Short (2002) develops the idea of practical or mission knowledge as an alternative to the conventional and dominant disciplinary knowledge production. He suggests the idea of practical or mission knowledge as a form of localised and needs based knowledge development. According to him, this practical knowledge is generated when needs arise in particular contexts where local issues provide the stimulus for enquiry. These include activities like education problems and health issues in particular contexts. These issues he says require particular forms 
of enquiry and action that often go beyond mere disciplinary ways of doing and knowing. He adds that this makes it a more flexible form of research and knowledge production which links to the peculiar needs of the problems in that context, Short (2002).

Practical knowledge comes into play in real human contexts where it is used carefully, to act in a real situation considered relevant to the task of learning through action. The solutions or answers arrived at in these processes are therefore not a simply created answer to intellectual questions but localized and contextualized responses to issues and problems. The knowledge developed is seen as appropriately selected and organized to fulfil educative functions related to questions connected problems and issues in particular contexts. This is often referred to as local or localised knowledge developed in response to contextualised issues and problems.

This form of knowledge seems appropriate for the more contextualised nature of EE "subject" knowledge for teacher education. This kind of knowledge does not pre-exist but develops in response to local issues and the questions generated from problems which occur in context requiring responsive "research" approaches. This also fits the contextualised nature of practicum periods that students engage in as it provides a particular localised context with its own issues and problems. Students, together with teachers and members of local (school) communities can be involved in organized enquiry-based teaching and learning processes required to deal with emerging issues and needs.

Students are immersed into local communities linked to schools at which they are placed during practicum periods. This provides for opportunities for expanding relationships beyond the school into communities which often have unique local issues. This further provides opportunities for teacher educators to connect with local knowledge workers who have the potential to contribute to highlighting, defining and providing information about issues that can lead to acting upon issues in these communities. By providing access to such networks teacher educators can facilitate links between local expertise (community) with academic expertise (teacher educators and students) to address local issues collaboratively. Teacher education (through the practicum) could thus act as a networking hub to establish, sponsor or develop transdisciplinary teams that can focus on key issues in the community through an educative position or stance. This can take the form of selection of content, suggesting communication and pedagogical strategies and supporting students as collaborative researchers of these issues. In this way students can become co-producers of knowledge in local contexts during practicum periods through collaborative processes in the networks suggested above. But what sort of opportunities would students / teachers need to develop the competencies / skills to enact such approaches to EE knowledge development? 


\section{Active learning - a focus for EE in teacher education}

Jickling and Wals (2008, 7-9) indicate that there are increasing tensions and contested views on the nature of education. They discuss two views which include that education is a "transmissive process" and, a contrasting position, that education is a "transformative or transactional" process. The former includes the unidirectional transmission of facts, values and skills from teachers to students. Content and learning outcomes are predetermined and prescribed and learning is a closed process by way of a unidirectional transmission of information from teacher to student. Formal teacher education systems as discussed earlier are generally organised in this manner, as it is efficient as a system and easy to control and administer. Education in terms of this understanding is thus about social reproduction and social efficiency and getting a message across and implanting agendas. The approaches mentioned above are largely responsible for the lack of meaningful (environmental) learning in many contexts as learners are not afforded opportunities to engage with real-life environmental issues and problem solving.

Jickling and Wals (2008) add that education can also be viewed as an emergent transactional or transformative process in which knowledge and meaning making are jointly socially constructed in a learning context by teachers and students. In this kind of setting knowledge is not fixed or static but rather co-constructed by learners together with other students / persons (Jickling and Wals 2008). Learners are actively involved in the learning process, often engaged in activities designed and implemented around local environmental issues.

Jickling and Wals (2008) use the two conceptions of education they describe to develop a heuristic, which illustrates two continuums for education as described. The horizontal line extends from authoritative to participatory approaches and the vertical line runs from transmissive to transformative. The intersecting lines provide for four quadrants which indicate how education might occur under the influences of the education understanding at the extreme of each of the lines and variations that can be developed along its course. These understandings of education processes are discussed briefly below and illustrated in the diagram that follows.

- Quadrant I: Education is authoritative and controlled, and outcomes are prescribed and linked to transmissive processes of teaching and passive learning. This can be linked to approaches such as education about environmental issues which provides knowledge and ideas of natural systems and social issues.

- Quadrants II and III have similarities and differences spread along the continuum. In quadrant II there are spaces for participation of students but this is linked to transmissive 
ideas probably coupled to instructions and limited discussions. Quadrant III similarly has authoritative and transformative goals for education. The transformative ideas might be moderated by the authoritative stances and dominant ideas linked to practices in education. The activities in these quadrants can be linked to education in environments, which often involves learning through experiences, observations, using equipment and forms of data collection. While students do observations and data collections it is often guided by work sheets and set questions.

- Quadrant IV is seen as being linked to both participatory actions and transformative ideas and is thus seen as being able to engender thought and action. It moves away from the technical and predetermined tendencies of transmissive approaches towards more transformative approaches. It thus opens up possibilities for individuals and communities action to deal with issues and questions in a self-determined, and responsive way (Jickling and Wals 2008, 18). This kind of education activity is in the range of education which is critical of dominant practices and has an open agenda for change and engenders coconstruction of knowledge in context and planning local action.

The heuristic provides spaces for adaptation in particular contexts which can aid in the evaluation of education initiatives linked to various environmental issues such as ecological degradation, social issues, and other global problems. The heuristic provides guidelines and frameworks for teacher educators, mentor teachers and even community members to engage in active learning in practicum contexts. This provides for guided learning which can gradually lead to more independent learning and knowledge development through collaborative research in local context as provided in the practicum setting and as described for quadrants III and IV.

Lucas (1972) coined three terms to describe broad approaches to environmental education namely education About, In / Through and For the environment which have gained wide acceptance in the field. About focuses on natural ecosystems and information related to social issues. Education in or through the environment is concerned with experiential learning in the environment and how this contributes to development of learner competencies and values clarification abilities. Education for the environment is and has a critical agenda of education for social change and transformation through action-based involvement in resolving environmental problems particularly in local contexts. 


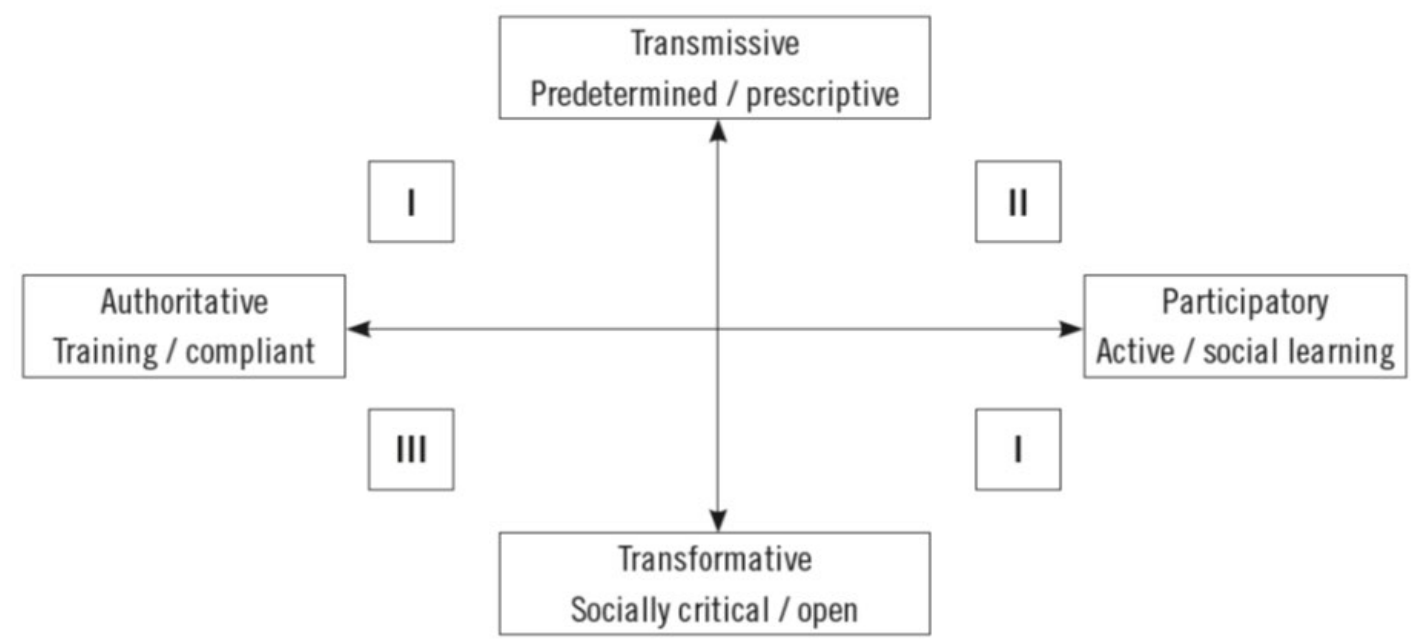

Figure 2: Positioning EE in terms of ideas for education (adapted from Jickling and Wals 2008)

Education for the environment as described above after Lucas 1972 is different and often not easily assimilated into conventional education practices. Rather this is similar to transformative education described above by Jickling and Wals (2008), and such approaches to EE are reformist and transformative and intent on challenging dominant practices and the status quo in general. The approaches to education highlighted by these authors link almost seamlessly to approaches to environmental education developed in the field as preferred pedagogical procedures and strengthens the probability for implementation of EE as part of teacher education programmes.

Brennen and Quinton (2020) indicate that the practicum period placement and the potential relationships with schools in a region creates opportunities for teacher educators and preservice teachers (students) to work with school communities to investigate and deliberate around the big issues challenging the lives of members of the communities associated with the schools.

The focus in EE is on continuously linking content with context in order to make learning real and relevant. Another important aim of EE is to develop independent, critical thinkers who have the knowledge, skills, awareness and attitudes to act in the interest of the environment on a personal and a societal level. The approaches of Short (2002) ideas of contextualised knowledge development (practical / mission) discussed earlier and practicum approaches in keeping with Jickling and Wals quadrants (III and IV) could be used to enable knowledge and pedagogical skills that will fit with EE developments and knowledge ideas that seem absent in teacher education programmes currently. The approaches discussed above could easily fit into and serve as catalysts to populate the spaces provided by situational learning and pedagogical learning in the knowledge mix in MRTEQ, (DHET (2011 / 2015) and could enable EE in curricula for preservice teachers locally and other contexts. 


\section{CONCLUSION}

Brennen (2017) highlights that the urgency of climate change and biosphere destruction pose challenges for education. This she says has implications that might require changes of practice for schools and thus for teacher education. Fein (1991) concurs that teacher education would need to make adjustments to ensure that teachers have the requisite knowledge and skills to ensure that the objectives of EE are achieved. The task thus befalls teacher education programmes to best prepare teachers for this responsibility.

But how best can these competencies be included in programmes to enable better EE implementation in education institutions? Brennen and Widdop Quinton (2020) suggests that teacher education programmes need to be open enough to allow for adaptability that will allow for renewal of practice and to avoid business as usual paralysis. This they suggest can be accomplished by working alongside our students, a context unique in teacher education, to problematize old narrative and construct new multiple narratives for the future. They indicate that narratives connected to place can help to build new discourses by drawing on multiple disciplines and expertises in particular contexts as is the case with practicum placements.

Teacher education by its very nature can thus serve as the mechanism to enable EE through inclusion of local environmental issues in the curricula of programmes using the practicum as a conduit and context for issue focused, active learning and co-production of knowledge. Latta and Field (2005) suggest that the field of teacher education needs to expand from the current narrow industrial models with fixed understandings and universal ways implementing practices. They suggest that processes and approaches that take into account the nature of teaching with all its complexities in varying contexts serve to drive programme development. Brennen (2017) further suggests that we in education include some of the debates linked to the societal crisis arising, especially the issues like climate change and global warming related to the environmental crisis. She states that we need to reconstruct our curricula and pedagogies and repurpose our institutions to ensure that educators will be invested in social justice and the survival of the human species.

The work of Short (2002) which enables the inclusion of local issues in curriculum and the work of Jickling and Wals (2008) which provides ideas for enabling students to be colearners and knowledge constructors provide ideas and spaces for such educational work to be accomplished. These approaches furthermore address major and local environmental issues in teacher education and also communities through the practicum processes as indicated above. I believe these approaches can assist with the reinvention of teacher education practices in a crisis ridden situation we live in, enabling the competencies and knowledge in future teachers which in a sense ensures that future generations will be informed and included in the environmental 
movement as indicated in sustainable goals for 2030. This in turn can contribute to a more socially just and sustainable future for humanity on planet earth.

\section{REFERENCES}

Brennen, Marie. 2017. Struggles for teacher education in the age of the Anthropocene. Journal of Education 69: 43-63.

Brennen, Marie, and J. Widdop Quinton. 2020. An ethical re-framing of curriculum for sustainability education. Curriculum Perspectives 40: 105-110.

Cochran-Smith, Marilyn, and Ken Zeichner. 2010. Studying teacher education: The report of the AERA panel on research and teacher education. New York: Routeledge.

Corney, Gregory, and Alan Reid. 2007. Student teachers' learning about subject matter and pedagogy in education for sustainable development. Environmental Education Research 13(1): 33-54.

Crist, Eileen. 2013. On the poverty of our nomenclature. Environmental Humanities 3(1): 129-147.

Davis, Brian, and David Sumara. 2012. Fitting teacher education in/to/for an increasingly complex world. Complicity: An International Journal of Complexity and Education 9(1): 40-40.

Department of Higher Education and Training. 2011. National Qualifications Framework act 67 of 2008. Policy on the Minimum Requirements for Teacher Education Qualification. Government Gazette No 34467.

Department of Higher Education and Training. 2015. National Qualifications Framework act 67 of 2008. Policy on the Minimum Requirements for Teacher Education Qualification. Updated 2015.

DHET see Department of Higher Education and Training.

Economist. 2018. Welcome to the Anthropocene. http://www.economist.com/node/18744401/ (Accessed 26 November 2019).

Edwards, Jane. 2011. "Towards effective socially critical environmental education: Stories from primary classrooms." Unpublished PhD thesis, Royal Melbourne Institute of Technology (RMIT), Melbourne, Australia.

Fein, John. 1991. "Accepting the dual challenge for professional development in environmental education." International Journal of Environmental Education and Information 10(1): 1-17.

Garm, Ninna and Gustav Karlsen. 2004. "Teacher education reform in Europe: The case of Norway; trends and tensions in a global perspective." Teaching and Teacher Education 20(7): 731-744.

Gough, Annette. 2009. "Not for want of trying: Strategies for re-orientating teacher education for Education for Sustainable Development (ESD)." Invited keynote address presented at the 12th UNESCO-APEID International conference, Bangkok, Thailand, 24-26 march 2009.

Gough, Annette. 2017. "Searching for a crack to let environment light in: Ecological biopolitics and education for sustainable development discourses." Cultural Studies of Science Education 12: 889-905.

Green, Witfield. 2012. "Policy on the Minimum Requirements for Teacher Education Qualifications." Presentation at a Bridge Teachers Upfront seminar, 7 February 2012. http://www.bridge.org. za/wp-content/uploads/2014/12/Teachers-Upfront-Presentation-W-Green-7-Feb-2012.pdf. (Accessed 20 November 2017).

Henderson, Joseph, David Long, Paul Berger, Constance Russel, and Andea Drewes. 2017. "Expanding the foundation: climate change and opportunities for educational research." Educational Studies 53(4): 412-425.

IPBES see International Science Policy Platform on Biodiversity and Ecosystem services.

International Science Policy Platform on Biodiversity and Ecosystem services. 2018. https://www.ipbes.net/news/media-release-worsening-worldwide-land-degradation-now$\%$ E32\%80\%98critical1\%E2\%80\%99-undermining-wellbeing-32. 
Jickling, Bob, and Arjen Wals. 2008. "Globalisation and environmental education. Looking beyond sustainable development." Journal of Curriculum Studies 40(1): 1-21.

Latta, Margaret, and James Field. 2005. "Flight from experience to representation: Seeing relational complexity in teacher education." Teaching and Teacher Education 21: 649-660.

Lucas, Arthur. 1972. "Environment and environmental education: Conceptual issues and curriculum implications." Ph.D. Dissertation, Ohio State University

McKeown-Ice, Rosalyn. 2000. "EE in the United States: A survey of preservice teacher education programs." The Journal of Environmental Education 32(1): 4-11.

Nsubaga, Yvonne. 2020. "Towards meaningful environmental learning beyond the classroom." In Environmental education: Principles and guidelines for teachers, ed. C. Reddy. Cape Town: Juta and company.

O Donoghue, Rob. 2005. Environment and active learning. NEEP guidelines for facilitating assessing active learning in $O B E$. Howick, Sharenet.

Ormond, Carlos, David Zandvliet, Milton McLaren, Patrick Robertson, Shannon Leddy, and Selina Metcalfe. 2014. "Environmental education as teacher education: Melencholic reflections from an emerging community of practice." Canadian Journal of Environmental Education 19: 160-179.

Pachuari, Rejandra, M. Allen, V. Barros, J. Broome, W. Cramer, R. Christ, and D. van Vuuren. (Ed.). 2014. Synthesis report of working groups I, II, and III to the fifth assessment report of the Intergovernmental Panel on Climate Change.

Reddy, Chris. 2017. "Environmental Education in teacher education: A viewpoint exploring options in South Africa." Southern African Journal of Environmental Education 33: 117-126.

Rocktrom, Johan, W. Steffen, K. Noone, A. Persson, F. S. Chapin, E. Lambin, and J. Foley. 2009. “A safe operating space for humanity." Nature 461(7263): 472-475.

Rosenberg, Eureta. 2009. Teacher education workbook for environment and sustainability education. Rhodes University, Grahamstown, Environmental Education and Sustainability Unit.

Sanford, Kenneth, Tim Hopper, and Lisa Star. 2015. "Transforming teacher education thinking: Complexity and relational ways of knowing." Complexity: An International Journal of Complexity and Education 22(2): 26-48.

Sanford, Kenneth, L. Williams, Tim Hopper, and C. McGregor. 2012. "Indigenous principles decolonizing teacher education: What we have learned." Educatio, 18(2): 18-34.

Sauve', Lucie. 2002. "Environmental education: Possibilities and Constraints." Connect XXVII(1-2).

Short, Edmund. 2002. "Knowledge and the educative functions of a university: Designing the curriculum of higher education." Journal of Curriculum Studies 14(2): 139-148.

Short, Phillip. 2010. "Responsible environmental action: Its role and status in environmental education and environmental quality." Journal of Environmental Education 41(1): 7-21.

Ulvik, Marit, and Kari Smith. 2011. "What characterises a good practicum in teacher education?" Education Inquiry 2(3): 517-536.

United Nations Educational, Scientific and Cultural Organization (2016). Final Report: Intergovernmental Conference on Environmental Education. Paris UNESCO.

UNEP. 1972. "The Belgrade Charter." Connect 1(1): 1-2.

UNESCO see United Nations Educational, Scientific and Cultural Organization.

United Nations Educational, Scientific and Cultural Organization. 2015. "Leading Education 2030." http://www.unesco.org/new/en/kathmandu/education/leading -education-2030/.

Van Petegem, Pieter, An Blieck, and Jelle De Pauw. 2007. Evaluating the implementation process of environmental education in preservice teacher education: Two case studies. Journal of Environmental Education 38(2): 47-54.

World Summit on Sustainable Development Johannesburg. 2002. https://wun.org/en/coww.nferences/ environment/johannesburg. 